\title{
A "conversa" e "aquele que não deve ser nomeado": um estudo de caso sobre a série americana Parenthood sobre discurso e representações raciais e de gênero
}

\author{
"The Talk", and the one who shall not be named: A case study on racial \\ and gender discourses on NBC's Parenthood.
}

\section{Samantha Joyce}

Doutora pela University of Iowa e mestrado em Rádio e TV pela San Francisco State University. É docente do Departamento de Comunicação da Saint Mary's College of California.

E-mail: samanthanjoyce@yahoo.com.

\section{Monica Martinez}

Doutora em Ciências da Comunicação pela ECA-USP, tem pós-doutorado pela Unesp e estágio doutoral pela Universidade do Texas (EUA). É docente do Programa de PósGraduação em Ciências da Comunicação da Universidade de Sorocaba (Uniso), de São Paulo.

\section{RESUMO}

A National Broadcasting Company (NBC) foi a primeira rede estadunidense a banir a palavra racista nigger de suas ondas de rádio nos anos 1950. Em 2012, novamente a

\section{0}

Dossiê Novas Faces do Poder - http://revistaecopos.eco.ufrj.br-ISSN 2175-8689 - v. 22, n. 2, 2019. 
palavra foi empregada na programação da rede, agora no aclamado drama Parenthood. Este artigo examina o racismo como construção discursiva, especialmente no que diz respeito à palavra banida, atualmente substituída pela expressão "The $N$ word", em português "a palavra N". O estudo se baseia numa correlação entre a tradição dos Estudos Culturais Britânicos de Stuart Hall com os Estudos Culturais da América Latina, analisando os discursos midiático, racial e de gênero, no contexto de uma ordem racial americana contemporânea que se descreve como pós-racista ao mesmo tempo em que a violência racial cresce no Brasil e no mundo.

Pallavras chave: Parenthood; Racismo; Relações de Gênero; Estudos Culturais; Representação; Narrativas.

\section{ABSTRACT}

NBC was the first American network to ban the racist word nigger from its radio waves in the 1950s. In 2012, the word was used again several times in the acclaimed drama Parenthood (NBC). This article examines racism as a discursive construction, especially in regards to the banished word nigger, currently replaced by "The $N$ word". This study is based on a correlation between Stuart Hall's British Cultural Studies tradition and Latin American Cultural Studies, analyzing media, racial and gender discourses in a contemporary American racial order that describes itself as post-racist, at a time in which racial violence grows in Brazil and in the world.

Keywords: Parenthood; racism; gender studies; cultural studies; representation; narratives.

\section{RÉSUMÉ}

National Broadcasting Company (NBC) a été le premier réseau américain à bannir le mot raciste nigger de ses ondes radio dans les années 1950. En 2012, le mot a également été utilisé dans la programmation réseau, désormais dans la célèbre série Parenthood. Cet article examine le racisme en tant que construction discursive, en particulier en ce qui concerne le mot supprimé, actuellement remplacé par l'expression "The $N$ Word», en Français «le mot N ». L'étude est basée sur une corrélation entre la tradition des études culturelles britanniques de Stuart Hall et des études culturelles en Amérique latine, analysant les discours médiatiques, raciaux et de genre dans le contexte d'un ordre racial américain contemporain qui se décrit comme post-raciste. en même temps que la violence raciale se développe au Brésil et dans tout le monde.

Mots clés: Parenthood; racisme; relations de genre; études culturelles; représentation; narratif. 
“O que é que há, pois, num nome?” indagou Shakespeare. Quase quatro séculos depois, a importância ou falta de importância dos referenciais é uma pergunta ainda relevante do ponto de vista filosófico, social e científico. Com isso em mente, o uso da expressão $N$ word, que substitui o insulto racial nigger no vocabulário estadunidense, particularmente nos discursos midiáticos, é o carro chave para a nossa análise da série Parenthood (Paternidade), exibida no Brasil pela GNT, canal de TV por assinatura ligado ao Grupo Globo. Vale a pena ressaltar que a "palavra N" não tem somente um significado ou tradução, mas é evocativa do conjunto das piores conotações raciais direcionadas aos afrodescendentes dos Estados Unidos. A análise textual discursiva de Parenthood ressalta que, ao contrário do que Shakespere propôs, 'o nome daquilo a que chamamos nigger, mesmo com outro nome - $N$ word - cheira igualmente mal", por serem termos igualmente racistas e preconceituosos. Além disso, a pesquisa evidencia uma diferença crucial entre as séries brasileiras e estadunidenses, onde estas últimas tem um caráter didático educativo fortemente presente.

A NBC foi a primeira rede de TV estadunidense a banir a palavra nigger (também referida como "A palavra com N") de suas ondas de rádio nos anos 1950. Duas décadas depois, na sitcom Sanford \& Son, a NBC usou a palavra, gerando controvérsias. Contudo, em 2012, a palavra e sua variação "com um 'A'” (nigga) foi usada várias vezes no aclamado drama Parenthood, da mesma emissora. 0 programa, que estreou em julho de 2010, já era o campeão de audiência da rede em 2011. 0 episódio The Talk (em português, “A Conversa”), que foi ao ar em 2012, apresentou à audiência conflitos sobre raça, racismo e o uso da "palavra N". Como Gray (2015) nos lembra, aqueles que controlam a mídia dominam os discursos de uma sociedade sobre si mesma. E Malachias (2017, p. 17) aponta que "por mais que o mundo avance, as teorias racistas do século XIX não ficaram no passado. Cotidianamente precisam ser rebatidas, pois a sua reformulação e propagação nas mídias e redes sociais evidenciam que o poder sobre quem pode ou não experienciar a dignidade 
humana vem de cima, das instituições que definem e controlam o conhecimento, e também vêm de dentro - crenças e estereotipias apreendidas, assimiladas e reproduzidas."

A mídia descreve, ensina e, fundamentalmente, autoriza uma visão particular da ordem racial na sociedade. Assim, as mídias, entre elas a televisão, seriam um dos locais possíveis para a projeção de nosso inconsciente, tanto coletivo (Jung, 2012) quanto reprimido (Freud, 2010), sendo, portanto, um dos lugares onde uma nova ordem racial poderia em tese ser primeiramente imaginada, depois criada e, finalmente, reproduzida. Consequentemente, é crucial estudar essa ordem racial por meio de sua representação midiática da raça e, mais especificamente, da "Palavra N", porque a TV não é apenas um local de luta por significação (Denzin, 1996): é, como Gray (1995) argumenta, o local onde os principais momentos raciais são encenados e interpretados para o público americano. Stuart Hall (1993) nos lembra que os textos midiáticos são um local de luta hegemônica, de negociação e reconfiguração da cultura e identidade popular.

Assim, a " $N$ word" é um terreno disputado, pois evoca várias reações e significados viscerais. Asim (2007, p. 3) nos lembra: ela pode representar atos de desafio, uma contranarrativa, desafiando o mito cultural de conquista e superioridade. Nesse sentido, os negros que fizeram campanha contra a narrativa majoritária a reescrevem. Como Asim nota, "quem pode, deve e por quê usá-la" também é território contestado digno de nosso exame crítico. Nossa análise de Parenthood aborda este tópico e ilustra ainda mais a "medida em que o desconforto racial continua a permear nossa cultura" (Asim, 2007, p. 3, tradução nossa).

Para Wagner (2012, p. 1, tradução nossa):

A palavra evoca reações fortes nos EUA, que variam em intensidade dependendo de como é usada, que forma é usada, quem é o falante e quem é o alvo. A palavra é tão abominável para tantos que é apenas usada como "a palavra N". Mesmo escrevê-la parece ofensivo e pode causar reações de arrepios e sentimentos de raiva ou vergonha. 
Esta pesquisa combina as tradições dos Estudos Culturais Britânicos com um corpo de trabalho derivado dos Estudos Culturais da América Latina, seguindo a tradição que gira em torno da relação entre o povo, o estado e a mídia acerca de como construir uma mídia verdadeiramente democrática dentro de economias de mercado livre. De acordo com Fox (1997, p. 184-295), isso requer um exame dos direitos e obrigações do indivíduo, o uso das mensagens mediadas pela audiência, organizações da sociedade civil e setores da mídia e da cultura cada vez mais autônomos, poderosos e transnacionais. Tais estudos também indagam sobre a própria natureza da comunicação, entendida aqui como uma "teia de palavras e desejos, memórias e estruturas de sentimentos, divisões sociais e descontinuidades culturais, apropriações e resistências midiáticas e com as quais as pessoas tecem suas vidas cotidianas" (Martín-Barbero; Munhoz, 1992, p. 6). Um texto transnacional da rede estadunidense NBC se encaixaria, a nosso ver, nesse critério.

Dentro da tradição latino-americana, essa análise de Parenthood também se baseia no que Joyce (2012) descreve como "análise textual aberta", que examina o texto da televisão em conjunto com os comentários da blogosfera sobre tal texto, para demonstrar as maneiras pelas quais os dois meios trabalham juntos como um fórum onde também visões alternativas sobre raça, racismo e relações raciais são discutidas. Portanto, este não é um estudo de recepção no sentido tradicional, mas também não é apenas uma análise textual, porém um estudo do meio social e internacional que Parenthood navega e que vê o texto como localizado em interações sociais (Joyce, 2012, p. 1-2). Enquanto a análise textual aberta investiga o meio social pelo qual o texto da TV navega, ela também depende da análise textual tradicional, ou seja, do próprio texto original, que serve como "dado" para essa discussão. A justificativa para tal abordagem é o entendimento de que "o significado é uma produção social e, como tal, está embutido em questões de poder" (Joyce, 2012, p. 1). A análise textual reconhece esse postulado e considera as condições de produção (e consumo) do texto. De acordo com essa abordagem, o texto não é o fim, mas o meio pelo 
qual estudamos um processo de significação, uma representação da realidade (AcostaAlzuru, 2003). Entendemos, portanto, a complexidade dos textos como algo que não pode ser reduzido a uma dicotomia simplista de "bom" e "ruim" (Bardin, 2011; Pessoni, 2015), nem visto à parte de sua contextualização socio-histórica.

Os Estudos Culturais Latino-Americanos enfatizam a necessidade de ir além do papel manipulador e comercial da mídia (García Canclini, 2001; Martín-Barbero, 1982; 1987; 1988; 1993). Embora Parenthood seja um produto comercial, isto é, feito com o objetivo de atrair público e, portanto, receita de publicidade, não se pode ignorar o fato de que as pessoas procuram nos produtos midiáticos mais do que meras regras abstratas da democracia devido ao descrédito nas organizações políticas. Logo, “o consumo pode ser um local de valor cognitivo, pode ser bom pensar e agir de maneira significativa que renova a vida social" (García Canclini , 2001, p. 45-47). Esse se constitui num componente essencial desta análise: o entendimento do consumo como uma forma de engajamento e prática política no contexto da mídia corporativa de livre mercado, em que pese a falta de confiança contemporânea nos representantes políticos.

O’Donnell (2012, p. 34-37) pontua que o público do programa é tão diverso quanto o próprio elenco. Em outras palavras, são membros da "família": homens, mulheres, avós, pais, filhos, todos representados em profundidade. No Brasil, onde as telenovelas são o melhor exemplo de narrativas midiáticas da indústria audiovisual, o exame da representação de atores afrobrasileiros nos últimos 50 anos de telenovelas brasileiras traz à tona o mito da chamada "democracia racial" (Joyce, 2012; Araújo, 2000). Como bem pontua Muniz Sodré (2010, p. 325):

Encoberto pela carnavalização das nossas relações sociais, esse preconceito é mais silencioso do que falante e, talvez por isto, demande perversamente como contrapartida o silêncio do Outro, portanto a sua 'inocência', no que diz respeito à dimensão racial das desigualdades sociais. 
0 pensador brasileiro também lembra a fragilidade da representação de identidades baseadas na "raça" em si, "quando este conceito já entrou em descrédito genético e antropológico" (Ibid, p. 326). Segundo Sodré, o "Brasil não é, evidentemente, o 'país mais racista do mundo', nem existe a polarização negro-branco, que é fundacional num país como os Estados Unidos" (Ibid, p. 326). Ele adverte que convém recordar a observação de Tzevetan Todorov de que o racismo não precisaria da existência de raças. "Do ponto de vista do indivíduo de pele escura, é evidente a existência de um mal-estar ético e antropológico, que nenhum discurso denegatório, seja ele de esquerda ou de direita, consegue ocultar" (Ibid, p. 326). Isso porque:

Cooptam-se os indivíduos, mas a ilusão civilizatória (a idealidade eurocêntrica) fica preservada. É como se o sujeito de pele clara dissesse: esse Outro (o negro) está entre nós, mas não é um de nós. Nos Estados Unidos, o impasse resolveu-se em separatismo, a partir de uma linha de diferença sanguínea estabelecida pelo sistema chamado Jim Crow: o Outro não é 'um de nós', mas é alguma coisa -negro, hispano, etc. - a ser apenas mantida à distância. Na solução brasileira (transigente, uma vez que o separatismo não entrou no ajuste civilizatório), proclama-se a proximidade do Outro, mas sem realmente deixá-lo ser enquanto tal, reconhecê-lo como singular, como um qualquer, dotado de fala própria. (Ibid, p. 326).

O geógrafo brasileiro Milton Santos (1926-2001) tem pensamento semelhante:

Costuma-se dizer que uma diferença entre os Estados Unidos e o Brasil é que lá existe uma linha de cor e aqui não. Em si mesma, essa distinção é pouco mais do que alegórica, pois não podemos aqui inventar essa famosa linha de cor. Mas a verdade é que, no caso brasileiro, o corpo da pessoa também se impõe como uma marca visível e é frequente privilegiar a aparência como condição primeira de objetivação e de julgamento, criando uma linha demarcatória, que identifica e separa, a despeito das pretensões de individualidade e de cidadania do outro. Então, a própria subjetividade e a dos demais esbarram no dado ostensivo da corporeidade cuja avaliação, no entanto, é preconceituosa (Santos, 2000, p. 1).

Em Parenthood, talvez a evidência mais interessante dessas observações esteja presente nos produtos anunciados, destinados a famílias contemporâneas de classe média, que variam de aveia Quaker e chocolate Reeses a iPhones, seguros, lojas de departamento, maquiagem e Home Depot. Os comerciais de maquiagem e coloração de cabelo sugerem que as mulheres são um alvo demográfico forte, e os produtos digitais sinalizam intenso 
uso das mídias sociais. Os produtos anunciados indicam estilos de vida confortáveis, ativos e típicos da classe média estadunidense contemporânea. Vale ressaltar os anúncios da Home Depot por serem pouco convencionais e apresentarem Steven Jordan, o diretor de arte da série, explicando como ele usa móveis que criam um "sentimento familiar" ou porque ele escolhe uma tinta específica para representar cordialidade e assim por diante tudo, claro, vendido na Home Depot.

Embora o elenco e público sejam diversos na visão de O’Donnell (2012, p. 34-37), um olhar mais atento indica que essa "diversidade" é composta por "lugares diversos dentro da família", em vez de propriamente uma diversidade de classe e/ou raça. Um exame dos produtos descritos acima e dos próprios membros do elenco deixam claro que o público de Parenthood é na verdade formado por brancos da classe média estadunidense. Além disso, uma vez que o show é ambientado em Berkeley, Califórnia, e ocasionalmente retrata relacionamentos birraciais (negros e brancos), podemos supor que esses personagens de classe média branca e/ou público sejam liberais. Assim, podemos supor que a "diversidade" em Parenthood é, portanto, concebida em termos de programação da NBC estadunidense que busca um consumidor branco de classe média com tendências liberais. Logo, a "missão" do programa é, de acordo com Budd \& Steinman, a de representar a raça de uma maneira que permita aos membros da audiência se sentirem bem consigo mesmos, às vezes por razões diferentes e contraditórias, de forma que retornem toda semana, prontos para consumir os anúncios das corporações que pagaram centenas de milhares de dólares por minuto.

García Canclini (2001, p. 45) afirma que o consumo não é simplesmente o poder de comprar mercadorias, observando ainda que não é apenas "um local não reflexivo de gastos inúteis". 0 autor vê no consumo "possibilidades de interação e reflexão crítica" (Ibid, p. 45). Essa visão está alinhada com a pesquisa atual de mídia latina, baseada em uma tradição histórica ligada aos movimentos sociais, à autorreflexividade e à práxis social, 
tidas como questões fundamentais para a maioria dos pesquisadores latino-americanos que dão grande importância às pessoas e à mídia, e usam modelos libertadores de pedagogia e comunicação. As afirmações de García Canclini são justificadas, pois ações políticas podem elevar os consumidores de textos televisivos ao patamar de cidadãos, com uma "concepção de mercado que não é apenas um lugar para a troca de mercadorias, mas como parte de interações socioculturais mais complexas". Dessa forma, o consumo é visto não tanto como a posse individual de objetos isolados, mas como a apropriação coletiva de mercadorias que atendem, além das necessidades materiais, igualmente as simbólicas.

\section{Recebendo e decodificando mensagens}

De acordo com Stuart Hall (1993), o público assume três leituras hipotéticas ao interpretar textos de mídia: 1) uma leitura dominante (quando o público responde a uma mensagem de mídia da maneira pretendida por seus produtores); 2) uma leitura negociada (que permite aos membros aceitar a leitura preferida, mas também resistir e modificá-la para dar conta de suas próprias experiências) e 3) uma leitura de oposição aos textos midiáticos, onde a posição social do leitor (raça, classe, gênero, sexualidade e assim por diante) os situa em oposição à interpretação hegemônica. Neste estudo, analisamos o enquadramento da $N$ word e de seus pontos de vista mutáveis nesta série como um poderoso local de luta, que assume vários significados, seja pelos membros da audiência, seja pelos personagens dentro da história: Crosby, o pai branco; Jasmine, a mãe negra; Jabbar, a criança birracial; e Double D, o artista negro que primeiro pronuncia a palavra.

Esta análise, portanto, se alinha com os estudos culturais, uma vez que ela descreve e interpreta processos de produção, "textos" e visões de audiência, "leituras" e mediações de mídia (Fox, 1997, p. 184, 199). Além do entendimento de que os textos são polissêmicos (Fiske, 1991), também aplicamos a "análise textual aberta" de Joyce (2012), que ilustra a metanarrativa criada em torno deste episódio, em particular examinando a interpretação 
de blogueiros de mídia e jornalistas de entretenimento, pois "o discurso do público sobre determinados programas de televisão se torna uma parte integral do próprio texto" (Joyce, 2012, p.30).

\section{Assistindo Raça}

Narrativas envolvendo raça e racismo não são novidade na TV estadunidense. A primeira família afroamericana apareceu em Good Times (1974) e, dez anos mais tarde, no The Cosby Show. Apesar das várias críticas a este último - como criar altas expectativas que eram inatingíveis para a maioria dos negros na época -, pesquisas indicam que o personagem Bill Huxtable teve um poderoso efeito positivo e direto sobre como os negros viam suas próprias famílias (Cummings, 1988, p.75-85).

Contudo, a pesquisa sobre o Cosby Show é complexa e multifacetada. Por exemplo, Sut Jhally e Justin Lewis (1992) argumentam que, por um lado, o programa retratou uma família negra bem-sucedida de maneira não sexista, fornecendo um modelo positivo para os afro-americanos ao negar estereótipos tradicionais, como "estúpidos" ou "preguiçosos". Por outro, ao programa também faltava realismo, uma vez que estabelecia altos padrões do "estilo de vida Huxtable" que os negros de verdade não conseguiam alcançar na época devido a razões sociais, econômicas e históricas.

Em meados da década de 1980, as redes americanas perceberam que programas de televisão orientados para os negros não somente eram lucrativos, mas também atraentes para o público branco. A negritude era tanto um sinal cultural complexo como também uma categoria de mercado em ascensão, da sua produção à circulação (Gray, 1995, p. 67). Um dos paralelos brasileiros é o de que, a partir dos anos 1980, também houve uma lenta mas progressiva ascensão do negro na dramaturgia da teleficção. Ainda assim, identificamos que em um terço das telenovelas produzidas pela Rede Globo até o final dos anos 1990, não havia nenhum personagem afrodescendente. Apenas em outro terço o número de atores 
negros contratados conseguiu ultrapassar levemente a marca de $10 \%$ do total do elenco. Considerando que o Brasil é um país em que cerca de $50 \%$ da população é formada por afrodescendentes, esta é uma demonstração contundente de que a telenovela nunca respeitou as definições étnico/raciais que os brasileiros fazem de si mesmos.

\section{A "N word"}

Com um elenco de 15 personagens, todos parte do clã Braverman, Parenthood representa as provações da vida cotidiana (Fallon, 2013). Em The Talk (A conversa), a $N$ word é usada como pano de fundo para um enredo que explora os significados da palavra, bem como as complicações de explicar a história da palavra para um menino - num certo sentido, cumprindo o título do show, uma vez que parenthood pode ser traduzido por "paternidade" e/ou "maternidade". Além disso, neste contexto, o programa "também aborda o privilégio branco de uma maneira refrescante e desinibida" (MacKenzie, 2012).

The Talk começa com a imagem de um branco: Crosby Braverman (Dax Shepard) trabalhando em seu estúdio de gravação, supervisionando uma sessão através de uma parede de vidro. Ele está com seu filho birracial de 8 anos, Jabbar (Tyree Brown). Pai e filho dançam com a música do artista Double D, que canta a variação da palavra Nigger - Nigga. Jabar pergunta a seu pai: "O que é um Nigga?" Crosby olha para seu filho em silêncio, enquanto a tela fica preta e há um corte para o intervalo comercial (MacKenzie, 2012). Mais tarde, durante o show, vemos uma cena de café da manhã onde Crosby conta à sua esposa negra, Jasmine (Joy Bryant), sobre o incidente. De acordo com MacKenzie, o diálogo que se segue é "um exemplo bem escrito de privilégios brancos arraigados e do modo como pessoas brancas bem-intencionadas podem se sentir desconfortáveis e até indignadas com o uso da palavra, mas nunca podem se relacionar verdadeiramente com o seu uso, poder e história" (MacKenzie, 2012). 
CROSBY: Primeiro de tudo, eu sinto muito, eu deveria ter previsto isso, mas não o fiz, e não pude prevenir que acontecesse. Nós estávamos em uma sessão de gravação e ele ouviu algumas palavras que ele não deveria ter ouvido.

JASMINE: Como o que?

CROSBY: Nigga.

JASMINE: O que você quer dizer: com um 'A' ou 'ER'?3

CROSBY: Eu acho que todas iterações.

JASMINE: Isso não importa.

CROSBY: Eu expliquei para ele. Eu disse você sabe, é uma palavra terrível como Voldemort, você sabe, de Harry Potter, aquele que não deve ser nomeado.

JASMINE: Sim, eu sei, e essa palavra não é nada como Voldemort.

CROSBY: Não, não, é pior. Eu disse que era pior, muito pior.

JASMINE: Então você acha que lidou com o assunto?

CROSBY: Sim, talvez não inteiramente, ele ainda estava confuso porque Double D disse isso, e ele queria saber por que ele tinha permissão para dizer isso.

JASMINE: E o que você disse?

CROSBY: Bem, eu fiquei meio confuso e disse, ele pode dizer isso porque é negro, e então Jabbar disse: "Eu sou negro, posso dizer isso?". E eu disse Voldemort de novo e depois fiquei nervoso.

JASMINE: Certo.

CROSBY: Me desculpe.

JASMINE: Você não precisa se desculpar. Quero dizer, é claro que você não saberia como lidar com isso. Eu preciso falar com ele. Eu preciso ter "a conversa" com ele.

CROSBY: Você terá a conversa com ele.

JASMINE: Sim, eu vou (...) Então eu vou lidar com ele, ok?

CROSBY: Ok (THE TALK, 2012, tradução nossa).

O diálogo acima serve como um excelente exemplo de como os textos são incorporados com múltiplos significados (Hall, 1993; Martín-Barbero, 1993). Como demonstra a pesquisa em análise textual, os significados culturais assumidos por um programa de TV são sempre algo mais do que as intenções dos produtores, editores e atores (Campbell, 1991; Joyce, 2012). Assim, os significados derivados do texto tornam-se difusos. Por um lado, o público e Crosby (o personagem) podem interpretar o comentário de Jasmine "é claro que você não saberia como lidar com isso" pelo menos de duas maneiras diferentes: ele é um pai inexperiente (os fãs do programa sabem que Crosby não sabia que ele tinha um filho até Jabbar completar 5 anos de idade); ou ele não pode lidar

\footnotetext{
${ }^{3}$ Variações da palavra nigga ou nigger (nota das autoras).
}

\section{1}


com esta situação porque ele (Crosby) é branco. MacKenzie (2012) aposta na primeira maneira, uma vez que este é um show sobre pais, e afirma:

Naquele momento, há um abismo entre Crosby e seu filho que simplesmente não pode ser preenchido. Parenthood não está tentando pregar; não há polícia moral aqui. Os personagens são simplesmente autorizados a serem pais imperfeitos, resolvendo um problema sem uma solução clara. Obviamente, há inúmeros pais brancos com filhos de cor, seja porque seus filhos são mestiços ou porque são adotados - então, embora seja chocante ver isso na televisão, é algo com que os pais lidam regularmente. A completa falta de experiência de Crosby com o racismo e a intolerância não é uma falha de caráter, mas o deixa mal equipado para falar com seu filho sobre o racismo e sobre o modo como isso se aplica à sua família.

Enquanto MacKenzie elogiou o diálogo acima, Bibel (2012) se refere a Crosby como um "pobre homem branco privilegiado... Tudo sobre sua reação está errado". Como mencionado acima, esta é a própria natureza das mensagens mediadas: elas são abertas a múltiplas interpretações e o público faz significados diferentes delas. Por exemplo, Campbell elogia o episódio e sua comparação da $N$ word, com a compreensão da cultura popular da referência intertextual a Voldemort, expressando que:

Crosby realmente se saiu bem com a discussão de Voldemort. Ele identificou perfeitamente o que "nigger" significa para quem não entende completamente o poder bruto e negativo da palavra. Voldemort era sua associação mais próxima, uma referência da cultura pop para uma palavra que todo mundo conhece, mas que a convenção exige que ninguém diga. A palavra é essencialmente sem sentido para Crosby, exceto pela história aprendida da frase e sua qualidade proibida. Tudo o que ele realmente entende é que você não diz isso, é ofensivo para as pessoas que não são ele, e isso carrega um peso que pode abalar o mundo frágil e inocente de Jabbar. Ele parecia entender isso informalmente, não pessoalmente, e o programa fez um bom trabalho ao se certificar de que vimos Crosby como ignorante, mas não intencionalmente pernicioso (CAMPBELL, 1991, tradução nossa).

Curiosamente, os pais de Jabbar não explicam que, por um lado, ele pode estar perpetuando a história racista por trás da palavra, ou que a palavra às vezes é usada ironicamente em um esforço de enfraquecer a palavra (Tate, 2003). Eles também não abordam o fato de que a palavra pode ser vista como uma "metáfora e símbolo do fracasso desta nação em fazer reparações satisfatórias de sua longa tradição de injustiça racial (Asim, 2007, p. 217). 
Então, “quem pode dizer, quem não deve e por quê?" Esta é uma pergunta que o telespectador pode se fazer enquanto espera a continuidade do diálogo entre Crosby e Jasmine. A situação em que Jabbar ouve a palavra pela primeira vez pode ser uma ilustração da descrição de Asim sobre obras de artistas de hip hop intelectualmente astutos que devem ser ouvidas como uma contra-narrativa do legado do niilismo desenfreado do gangsta rap. Por outro lado, como o autor postula, parte do gangsta rap mantém viva a agenda da supremacia branca ao glorificar estereótipos como a preguiça, a criminalidade e a insaciabilidade sexual (Asim, 2007, p. 222).

Esta é uma questão complicada e difícil de responder, mas geralmente se refere à posição social e ao contexto racial dos que proferem a palavra. Como Wagner (2012) afirma:

Jabbar, inadvertidamente, ouve vários músicos afro-americanos falando de maneira casual entre si e usando uma derivação da $N$ word aparentemente sem nenhum conflito emocional. No entanto, Crosby é caucasiano, tem uma compreensão superficial de caucasiano sobre essa palavra sensível e sente grande ansiedade ao tentar descobrir como responder às perguntas de Jabbar. Jasmine, que é afro-americana, tem uma visão mais pessoal do uso e da história da palavra (tradução nossa).

Além disso, como afirma Asim, o uso da palavra às vezes pode ser usado para gerar novos significados. 0 autor explica que Mos Def justifica o uso da palavra explicando que "quando nos chamamos de nigga, tomamos uma palavra que tem sido historicamente usada pelos brancos para nos degradar e oprimir, (...) uma palavra que tem tantas conotações negativas, e [a transformamos] em algo bonito, algo que chamamos de nosso. Eu sei que isso soa clichê, mas realmente se torna um 'termo carinhoso'" (apud Asim, 2007, p. 224, tradução nossa).

\section{Jasmine e a representação da feminilidade negra}

Como bell hooks (1992, p. 128) nos lembra, as mulheres negras, como espectadores críticos, fazem mais do que resistir, mas participam de uma ampla gama de relações de 
olhares; elas contestam, resistem, revisam, interrogam e inventam em múltiplos níveis. Já Boylorn (2008, 413-433) argumenta que as mulheres negras na televisão são geralmente representadas por meio de estereótipos e sugere que as negras devem usar um olhar de oposição quando leem textos televisivos sobre (supostamente) elas próprias. Ele sugere que na TV as mulheres negras são extremamente educadas ou abandonam o ensino médio; são ambiciosas ou preguiçosas; sexy ou feias. Além disso, o autor explica que os relacionamentos televisivos das mulheres negras com um homem são sempre assustadores, porque ou ela é muito educada e independente para precisar ou querer um homem ou porque é desesperada e perdida sem ele. De acordo com Boylorn, essas falsas representações do que poderia significar ser negra e mulher na televisão deixam oportunidades limitadas para uma mulher negra ser apresentada fora dos limites esperados.

Este certamente não é o caso da personagem Jasmine, como pode ser ilustrado pelo seu background. Ela é uma dançarina e professora educada, talentosa e bem sucedida, mas também esposa compreensiva para com os limites de seu parceiro e mãe amorosa. Assim, do ponto de vista de relações de gênero (Martinez, Lago e Lago, 2016), ao assumir o controle da discussão sobre a $N$ word com seu filho birracial Jabbar, Jasmine evidencia consciência da complexidade de seu papel social e racial, uma vez que quando ela deixa seu filho (e o público) saber que foi sua mãe, não seu pai, que teve essa mesma conversa com ela quando era uma garotinha, fica claro que ela também é uma boa filha. Nesta cena íntima vemos Crosby, Jasmine e Jabbar sentados à mesa de jantar. Diferentes closes são usados para enfatizar a expressão facial de cada personagem:

JASMINE: Então, eu quero falar com você sobre essa palavra que você ouviu no estúdio. Eu sei que você tem algumas perguntas.

JABBAR: Bem, o papai disse que os negros às vezes dizem isso, mas eu não tenho permissão para isso.

JASMINE: Sim. Eu sei que é muito confuso. Eu vou te dizer de onde vem essa palavra. Essa palavra vem da palavra Nigger. É uma palavra muito malvada que pessoas 
brancas usam para chamar pessoas negras e isso significa que não somos tão bons, nem tão inteligentes ou tão humanos quanto eles.

JABBAR: Por que as pessoas dizem isso?

JASMINE: Bem, muito, muito tempo atrás, pessoas brancas possuíam pessoas negras como escravos, mas já percorremos um longo, longo caminho. Você sabe quando comemoramos o dia de Martin Luther King? Bem, ele ajudou a tornar as coisas iguais. E legalmente são, mas às vezes não parece que são. Então, você tem alguma pergunta ainda?

JABBAR: As pessoas podem me chamar assim?

CROSBY: Ai delas.

JASMINE: Eles podem. Eu lembro que tinha a sua idade quando minha mãe conversou comigo sobre tudo isso. E foi muito reconfortante quando ela disse que o mundo era melhor do que quando ela era uma garotinha. $E$ agora estou sentado aqui com você tendo a mesma conversa. E é ainda melhor. Você sabe, minha mãe costumava sonhar com o dia em que teríamos um presidente negro.

CROSBY: E agora temos, Obama.

JASMINE: É verdade, nós vivemos em bons momentos agora. E eu não quero que você se preocupe ou tenha medo disso.

(Crosby olha para seu filho, choroso).

JASMINE: Crosby há algo que você gostaria de acrescentar?

CROSBY: Não, isso foi perfeito.

JASMINE: Então você sabe de onde vem a palavra (The talk, 2012, tradução nossa).

O episódio explora as perspectivas de ambos os pais e permite que suas experiências sejam a base para suas decisões. Em última análise, Jasmine explica, de forma didática, a história da palavra para Jabbar. Em alguns aspectos, ela também está ensinando a questão a Crosby, seu marido. Talvez o momento mais revelador da conversa seja quando Jabbar pergunta: "As pessoas podem me chamar assim?". Enquanto Crosby responde com um doloroso "ai delas", Jasmine respira e explica ao filho que "podem". Em última análise, "Bryant retratou a combinação única de determinação e tristeza de Jasmine lindamente. Jasmine saiu tão sábia e forte neste episódio" (MacKenzie, 2012).

Com sua conversa pessoal e histórica, Jasmine seduz não apenas o público, mas também o marido Crosby. Após a conversa com o filho, ela uma segunda vez é representada como uma esposa amorosa e inteligente, lidando em família com complicadas questões raciais: 
CROSBY: Eu estava pensando no ótimo trabalho que você fez com ele na noite passada. Você foi realmente incrível. Você estava certa em lidar com isso.

JASMINE: Obrigada, acho que ele entendeu a maior parte.

CROSBY: Oh, ele entendeu completamente. Quero dizer, até eu entendi de uma forma que nunca tinha. Eu estava olhando vocês dois, a conexão, e me senti um pouco irrelevante.

JASMINE: Não, desculpe, eu não queria fazer você se sentir assim.

CROSBY: Não, não, não, você não fez nada, eu só, você sabe, eu odeio pensar que há coisas que ele vai experimentar que eu, você está certa, não posso me relacionar, você sabe.

JASMINE: Sim. Mas haverá outras ocasiões em que você pode se relacionar e eu não posso. Ele é um menino, então ele vai passar por todos os tipos de coisas que eu não vou entender, nem quero (risos).

CROSBY: Sim, eu acho que é diferente, isso já aconteceu com você? Você sabe, onde você foi feita se sentir inferior?

JASMINE: Sim, algumas vezes.

CROSBY: Sinto muito. Se isso acontecesse com ele, isso me mataria (The talk, 2012, tradução nossa).

Mais uma vez, Jasmine carrega a cena. A confissão de Jasmine de que ela "se sentiu inferior é genuína e tocante - mas o telespectador não deixa de notar que o pedido de desculpas também é ineficaz" (MacKenzie, 2012). Outros críticos concordam. Wagner afirma que "para uma primeira discussão, Jasmine agiu lindamente; até Crosby aprende com ela. Sua explicação começa com o processo de entender que a $N$ word tem sido usada historicamente para rebaixar os afro-americanos, para infligir dor, subjugar, implicar poder e se referir à escravidão e à segregação (Wagner, 2012).

Como lembra Fiske, os textos são polissêmicos. Assim, Richardson (2012) o critica:

O silêncio de Parenthood sobre a negritude de seus personagens negros reflete a disposição de ignorar a realidade das experiências das pessoas de cor na ânsia de avançar para o pósracismo. Isso sublinha duas coisas: as coisas mudaram, há um desejo coletivo de igualdade. Mas o principal problema permanece: ainda é um campo de jogo branco, com personagens principais brancos que querem desfrutar de um mundo sem racismo. Eles são os únicos que decidiram seguir em frente (tradução nossa).

Os textos televisivos são densos, ricos, complexos e incorporados de multiplicidades de significados e leituras, articulados e rearticulados por audiências, criadores e outros. Por 
exemplo, quando Crosby expressa frustração por Jasmine assumir a liderança na conversa porque "ela é negra":

JASMINE: Amor, você tem que respeitar o fato de que eu tenho um entendimento sobre o assunto que você não tem. E o fato é que a palavra significa algo diferente para Jabbar porque ele é negro.

CROSBY: Tudo bem. Isso é justo. Mas ele também é meio branco.

JASMINE: Certo, então você sabe, ele pode usar o "cartão branco" dele quando for parado pela polícia no trânsito por ser negro. Ele pode apenas dizer: "na verdade sou meio branco" (The talk, 2012, tradução nossa).

A reação de Bibel (2012) ao diálogo acima é ilustrativa dos vários significados polissêmicos produzidos pelos espectadores desse local discursivo "telecultural":

Ele [Crosby] até reclama que Jasmine não está ouvindo-o porque ele é branco. Realmente não lhe ocorre que Jasmine saiba mais sobre racismo do que ele, ou que isso é o que Jabbar precisa. Ele até mesmo afirma que Jabbar também é meio branco, como se isso de alguma forma impedisse que seu filho experimentasse racismo. Jasmine explica a palavra a seu filho, dizendo que os brancos historicamente a usam para difamar os negros. Isso parece ser um choque tão grande para Crosby quanto para Jabbar. Jabbar é surpreendentemente ignorante da história negra e, aparentemente, até mesmo inconsciente da escravidão, embora saiba quem é Martin Luther King. Ele se pergunta se alguém vai chamá-lo assim. Jasmine diz que isso pode acontecer, mas o mundo é melhor do que costumava ser (tradução nossa).

Por outro lado, MacKenzie (2012) elogiou o diálogo: "Não há animosidade em seu tom [Jasmine], ela não culpa Crosby por sua ingenuidade ou ignorância. Ela é verdadeira, inteligente e faz o melhor que pode como mãe enfrentando circunstâncias infelizes."

E Fallon sugere que o público assume uma "leitura dominante" do texto (Hall, 1993) e que a única "maneira verdadeiramente apropriada" de reagir é "chorando com os Bravermans" (Fallon, 2012). 


\section{Considerações não conclusivas}

Nosso estudo correlaciona os Estudos Culturais britânicos e latino-americanos a um estudo de um programa de TV estadunidense do horário nobre e sua representação de raça, racismo e de termos como a $N$ word. Acrescentamos à tradição que gira em torno da relação entre o povo, o estado e a mídia, e sobre como construir uma mídia verdadeiramente democrática dentro de economias livres de Mercado - o que requer um exame dos usos das mensagens mediadas pelas audiências, as organizações da sociedade civil e as indústrias de mídia e cultura cada vez mais autônomas, poderosas e transnacionais. Além do modelo de Hall (1993) de codificação/decodificação e da tradição dos Estudos Culturais, o estudo também foi baseado em estudos sobre polissemia (Fiske, 1991), o que explica a gama de significados e reações gerados pela interação entre audiências, criadores e tomadores de decisão das redes de TV, bem como o modelo de "análise textual aberta" de Joyce, que ilustra a metanarrativa criada em torno de textos particulares de televisão por telespectadores/leitores do programa - uma narrativa que se torna parte integrante do próprio texto - e, finalmente, examinando representações estereotipadas tradicionais dos negros na TV. A metanarrativa foi examinada através da "análise textual aberta", analisando o texto televisivo em conjunto com os comentários da blogosfera sobre tal texto, demonstrando, assim, como as mídias (no caso TV e internet) trabalham juntas como um tipo de fórum público onde visões arraigadas e alternativas sobre raça, racismo e relações raciais são discutidas.

Neste sentido, Parenthood ofereceu, de um modo didático, uma maneira refrescante de lidar com o problema do racismo na televisão e na cultura estadunidense contemporânea. Como afirma Seiter, "os estereótipos contêm uma avaliação que justifica as diferenças sociais" e são uma tentativa de explicar e justificar desigualdades óbvias em uma sociedade cuja ideologia oficial é a igualdade racial” (Seiter, 1986, p. 16-17). Como 
discutimos, The Talk ofereceu uma nova maneira de lidar com estereótipos por meio de sua representação da personagem Jasmine, mas também dos usos e explicações da $N$ word.

Os personagens foram capazes de dizer a palavra na televisão e discutir seu significado, história e implicações. Como MacKenzie afirma, "este é um terreno que não tem sido coberto pela TV aberta" e é "uma história que fica com o espectador da melhor maneira, fazendo você pensar sobre história, experiência e racismo internalizado em um episódio muito especial". Qualquer pai faria bem em assistir a este episódio escrito e interpretado habilmente (MacKenzie, 2012).

Qual é o papel da televisão? Como a TV pode contribuir para um debate público crítico sobre raça e racismo? Como podemos exigir múltiplas representações de realidades que não estão ligadas a estereótipos humilhantes ou assumidos? Quais são as leituras derivadas de um texto de televisão? E, finalmente, a relação entre mídia, mudança social e televisão roteirizada como um local de discursos públicos sobre identidade, política de representação, papéis de gênero (Martinez; Lago e Lago, 2016), bem como questões sobre raça, política e democracia, são questões que continuamos a considerar enquanto seguimos com nossas indagações. Programas como Parenthood continuam impulsionando tais investigações porque, como Dewey (1991), acreditamos que o caminho para alcançar a “comunidade ideal” é por meio da comunicação e que, modificando as maneiras pelas quais usamos as tecnologias de mídia, podemos de fato alcançar um público que tenha um debate participativo, compreensivo e crítico.

\section{Referências bibliográficas}

ACOSTA-ALZURU, C."I am not a feminist ... I only defend women as human beings": the production, representation, and consumption of feminism in a telenovela. Critical Studies in Media Communication, v. 20, n. 3, 2003, p. 269-294. 
ARAÚJO, J. Z. A negação do Brasil: o negro na telenovela brasileira. São Paulo: Senac, 2000.

ASIM, J. Who can say it, shouldn't and why. Boston: Houghton Mifflin Company, 2007.

BIBEL, S. How 'Parenthood' tackled 'the N-word,' and why Crosby's reaction was off. 2012. Disponível em: https://my.xfinity.com/blogs/tv/2012/10/03/how-parenthood-tackledthe-n-word-and-why-crosbys-reaction-was-off/. Acesso 29 ago 2018.

BOYLORN, R. M. As seen on TV: an autoethnographic reflection on race and reality television. Critical Studies in Media Communication, v. 25, n. 4, 2008, 413-433.

CAMPBELL, R.. 60 Minutes and the news: A mythology for middle America. Chicago, IL: University of Illinois Press, 1991.

CUMMINGS, M. The changing image of the black family on television. Journal of Popular Culture, v. 22, p.75-85, 1988.

GARCÍA CANCLINI, N. Consumers and citizens: globalization and multicultural conflicts. Minneapolis: The University of Minnesota Press, 2001.

DENZIN, N. K. [Review of] Herman Gray, Watching race: television and the struggle for "blackness". Contemporary Sociology, v. 25, n. 5, p. 688-689, 1996.

DEWEY, J. The Public and its problems. Athens, Swallow Press, 1991.

FALLON, K. "Parenthood": Season 4's 10 most tear-jerking moments. From a heartbreaking cancer reveal to a tragic breakup, the biggest Kleenex moments from the underrated NBC gem's fourth season. Disponível em:

$<$ http://www.thedailybeast.com/articles/2013/01/22/parenthood-season-4-s-10-mosttear-jerking-moments-video.html>. Acesso em 16 out. 2013.

FISKE, J. Television culture. New York: Routledge, 1991.

FOX, E. "Media and Culture in Latin America". In: CORNER, J.; SCHELSINGER, P; SILVERSTONE, R. (Org.), International media research: a critical survey. New York: Routlege, 1997, p. 184-295.

GRAY, H. Watching race: television and the struggle for 'blackness'. Minneapolis: University of Minnesota Press, 1995. 
JOYCE, S. N. Brazilian telenovelas and the myth of racial democracy. Plymouth, UK: Lexington Books, 2012, p. 1-2.

HALL, S. "Encoding, Decoding". In: S. During (Org.). The cultural studies reader. New York, Routledge, 1993, p. 90-103.

HOOKS, B. Black looks: race and representation. Boston, South End Press, 1992, p. 128.

FREUD, S. A interpretação dos sonhos. São Paulo: Folha de S.Paulo, 2010.

JHALLY, S.; LEWIS, J.. Enlightened racism: the Cosby Show, audiences and the myth of the American dream. Bolder, Colorado: Westview Press, 1992.

JUNG, C. G. Os arquétipos e o inconsciente coletivo (OC 9/1). 8. ed. Petrópolis, RJ: Vozes, 2012.

MACKENZIE, C. A. "Parenthood' tackles the N-word with grace, honesty, and that Braverman bravery, 2 October 2012. Disponível em: <http://blog.zap2it.com/frominsidethebox/2012/10/parenthood-tackles-the-n-wordwith-grace-honesty-and-that-braverman-bravery.html>. Acesso em: 10 set. 2013.

MALACHIAS, R. Comunicação, educação e arte. Interfaces para o enfrentamento do racismo. Revista Crioula (USP), v. 19, p. 17, 2017.

MARTÍN-BARBERO, J.; MUNOZ, S. Televisión y melodrama. Bogotá, Colombia, Tercer Mundo Editores, 1992, p. 6.

MARTÍN-BARBERO, J. Challenges for communication research in Latin America. Communication and Culture, v. 9, 1982, p. 99-113.

. Communication from culture: the crisis of the national and the emergence of the popular. Media, Culture and Society, v. 10, 1988, p.447-465.

. Communication, culture and hegemony: from media to mediations. London/Newbury Park: Sage, 1993.

. From media to mediations: Communication, culture and hegemony. Mexico City:

Ediciones G. Gili, 1987.

MARTINEZ, M.; LAGO, C.; LAGO, M. C. S. Estudos de gênero na pesquisa em jornalismo no

$$
291
$$

Dossiê Novas Faces do Poder - http://revistaecopos.eco.ufrj.br-ISSN 2175-8689 - v. 22, n. 2, 2019. 
Brasil: uma tênue relação. Famecos, 2016.

SANTOS, M. A. Ser negro no Brasil hoje. Folha de S.Paulo - Caderno Mais, São Paulo, 7 mai 2000.

SODRÉ, M. Sobre a identidade brasileira. I/C - Revista Científica de Información y Comunicación. Sevilla, 2010.

O’DONNELL, V. Television criticism. Califórnia: Sage, 2012.

RICHARDSON, K. In an Obama age, shows like 'Parenthood' flatter us into believing race no longer matters - and avoid hard truth. Salon.com. 2012. Disponível em: < https://www.salon.com/2012/01/18/tvs_eerie_new_race_less_world/>. Acesso em: 29 ago 2018.

SEITER, E. Stereotypes and the media: a re-evaluation. Journal of Communication, v. 36, n. 2, 1986, p. 16-17.

TATE, G. Everything but the burden. Broadway Books: New York, 2003.

THE TALK: Watson, S. (escritor); Norris, P. R. (Diretor). New York: NBC, 2012. Episódio 4, Temporada 4.

WAGNER, S. The experts speak, 2012. Disponível em: http://nbcparenthood.tumblr.com/post/62431805874/the-experts-speak-welcome-backparenthood $>$. Acesso em 11 set 2018. 